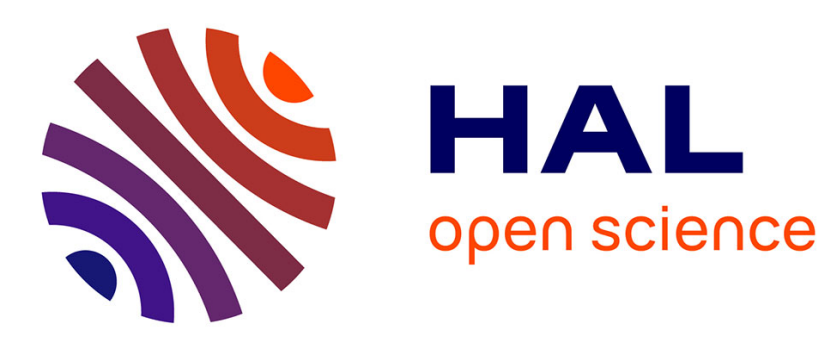

\title{
Nitrogen deficiency in Arabidopsis affects galactolipid composition and gene expression and results in accumulation of fatty acid phytyl esters
}

Nicole Gaude, Claire Bréhélin, Gilbert Tischendorf, Felix Kessler, Peter Dörmann

\section{To cite this version:}

Nicole Gaude, Claire Bréhélin, Gilbert Tischendorf, Felix Kessler, Peter Dörmann. Nitrogen deficiency in Arabidopsis affects galactolipid composition and gene expression and results in accumulation of fatty acid phytyl esters. Plant Journal, 2007, 49 (4), pp.729-739. 10.1111/j.1365-313X.2006.02992.x . hal-02347115

\section{HAL Id: hal-02347115 \\ https://hal.science/hal-02347115}

Submitted on 5 Nov 2019

HAL is a multi-disciplinary open access archive for the deposit and dissemination of scientific research documents, whether they are published or not. The documents may come from teaching and research institutions in France or abroad, or from public or private research centers.
L'archive ouverte pluridisciplinaire $\mathbf{H A L}$, est destinée au dépôt et à la diffusion de documents scientifiques de niveau recherche, publiés ou non, émanant des établissements d'enseignement et de recherche français ou étrangers, des laboratoires publics ou privés. 


\title{
Nitrogen deficiency in Arabidopsis affects galactolipid composition and gene expression and results in accumulation of fatty acid phytyl esters
}

\author{
Nicole Gaude ${ }^{1}$, Claire Bréhélin ${ }^{2}$, Gilbert Tischendorf ${ }^{3}$, Felix Kessler ${ }^{2}$ and Peter Dörmann ${ }^{1, *}$ \\ ${ }^{1}$ Department of Molecular Physiology, Max Planck Institute of Molecular Plant Physiology, Am Mühlenberg 1, 14476 Golm, \\ Germany, \\ ${ }^{2}$ Institute of Biology, University of Neuchâtel, rue Emile Argand 11, CH-2007 Neuchâtel, Switzerland, and \\ ${ }^{3}$ Institute of Plant Physiology, Free University of Berlin, Königin-Luise-Straße 12-16, 14195 Berlin, Germany
}

Received 22 September 2006; accepted 17 October 2006.

*For correspondence (fax +49 331567 8250; e-mail doermann@mpimp-golm.mpg.de).

\begin{abstract}
Summary
Nitrogen is an essential nutrient for plants because it represents a major constituent of numerous cellular compounds, including proteins, amino acids, nucleic acids and lipids. While $\mathrm{N}$ deprivation is known to have severe consequences for primary carbon metabolism, the effect on chloroplast lipid metabolism has not been analysed in higher plants. Nitrogen limitation in Arabidopsis led to a decrease in the chloroplast galactolipid monogalactosyldiacylglycerol (MGDG) and a concomitant increase in digalactosyldiacylglycerol (DGDG), which correlated with an elevated expression of the DGDG synthase genes DGD1 and DGD2. The amounts of triacylglycerol and free fatty acids increased during $\mathbf{N}$ deprivation. Furthermore, phytyl esters accumulated containing medium-chain fatty acids $(12: 0,14: 0)$ and a large amount of hexadecatrienoic acid (16:3). Fatty acid phytyl esters were localized to chloroplasts, in particular to thylakoids and plastoglobules. Different polyunsaturated acyl groups were found in phytyl esters accumulating in Arabidopsis lipid mutants and in other plants, including 16:3 and 18:3 species. Therefore $\mathrm{N}$ deficiency in higher plants results in a co-ordinated breakdown of galactolipids and chlorophyll with deposition of specific fatty acid phytyl esters in thylakoids and plastoglobules of chloroplasts.
\end{abstract}

Keywords: phytyl ester, nitrogen deficiency, monogalactosyldiacylglycerol, digalactosyldiacylglycerol, chloroplast, chlorophyll.

Introduction

In contrast to animals, yeast and many bacteria, higher plants contain large amounts of phosphorus-free glycoglycerolipids: monogalactosyldiacylglycerol (MGDG), digalactosyldiacylglycerol (DGDG) and sulfoquinovosyldiacylglycerol (SODG). Glycoglycerolipids are not distributed ubiquitously across the subcellular compartments. MGDG, DGDG and SQDG are particularly enriched in chloroplasts. Their high abundance in thylakoids of leaves led to the hypothesis that galactolipids have important functions in photosynthesis (reviewed by Benson, 1971; Douce and Joyard, 1980). Indeed, analysis of Arabidopsis mutants deficient in MGDG (mgd1) or DGDG $(d g d 1, d g d 2)$ synthesis revealed that galactolipids are essential to support growth and photosynthesis (Dörmann et al., 1995; Jarvis et al., 2000; Kelly et al., 2003). Under optimal conditions, the amounts of galactolipids in extraplastidial membranes are very low. However, during phosphate deprivation, biosynthesis of SODG and DGDG and the expression of sulfolipid and galactolipid genes are upregulated (Awai et al., 2001; Essigmann et al., 1998; Härtel et al., 2000; Kelly and Dörmann, 2002; Kelly et al., 2003). Under phosphate-limiting conditions, DGDG replaces phospholipids in plastidial and extraplastidial membranes (Andersson et al., 2003; Härtel et al., 2000; Jouhet et al., 2004).

In contrast to phosphate deficiency, not much is known about the impact of other nutrient deficiency stresses on membrane lipid composition in higher plants. Nitrogen is one of the most important macronutrients and is often limiting for plant growth. It is taken up via the roots as nitrate or ammonia, and nitrate is reduced to nitrite and ammonia, 
which is subsequently employed for amino acid synthesis (for reviews see Crawford, 1995; Stitt, 1999). Nitrogen deficiency causes strong changes in $\mathrm{N}$ and $\mathrm{C}$ metabolism, and in particular affects the abundance of amino acids and proteins (Scheible et al., 2004; Wang et al., 2003). Furthermore, N deprivation affects chlorophyll content and the abundance of thylakoid membranes in chloroplasts of algae and cotton (García-Ferris et al., 1996; Malavolta et al., 2004). However, the impact of $\mathrm{N}$ deficiency on membrane lipid turnover in chloroplasts, or the fate of acyl groups released from membrane lipids, have not been analysed in higher plants.

To study the effect of nutrient supply on the regulation of lipid biosynthesis and turnover, the lipid composition and expression of galactolipid genes were determined in Arabidopsis plants grown under $\mathrm{N}$ deficiency and compared with phosphate deficiency. From these studies, it became clear that DGDG synthesis is stimulated in plants during nutrient-deficiency conditions other than phosphate deprivation. Furthermore, large amounts of acyl groups removed from galactolipids are deposited as fatty acid phytyl esters (FAPEs) during $\mathrm{N}$ deprivation, and these esters are localized to thylakoids and plastoglobules of chloroplasts.

\section{Results}

\section{Nitrogen deficiency affects galactolipid composition in leaves}

Phosphate deprivation is known to alter membrane lipid composition in plants, because it leads to a decrease in the amounts of phospholipids while DGDG and SQDG increase (Essigmann et al., 1998; Härtel et al., 2000). Therefore it was important to demonstrate that $\mathrm{N}$ deprivation did not affect the phosphate status of the plant. For this reason, the contents were determined of chlorophyll, fatty acids and inorganic phosphate in plants grown without N, phosphate or magnesium (Figure 1). Magnesium deprivation was employed as an alternative means to reduce the abundance of chlorophyll and of the entire photosynthetic machinery. Phosphate limitation resulted in a decrease in the contents of chlorophyll, fatty acids and inorganic phosphate. Growth without $\mathrm{N}$ also affected chlorophyll and fatty acid content, but similar to $\mathrm{Mg}$ deficiency, had no measurable effect on phosphate (Figure 1). The reduction in fatty acid content during $\mathrm{N}$ deprivation suggested that about $25 \%$ of chloroplast lipids were degraded. Electron microscopy was used to assess the impact of $\mathrm{N}$ or phosphate deficiency on chloroplast ultrastructure in leaf mesophyll cells (Figure 2). Phosphate deprivation resulted in the enlargement of starch granules in the stroma (Figure 2c). Nitrogen deficiency had a severe impact on chloroplast ultrastructure, because a high number of large starch granules and electron-dense plastoglobules accumulated in the stroma (Figure 2b). The thylakoid membrane system was barely visible because it

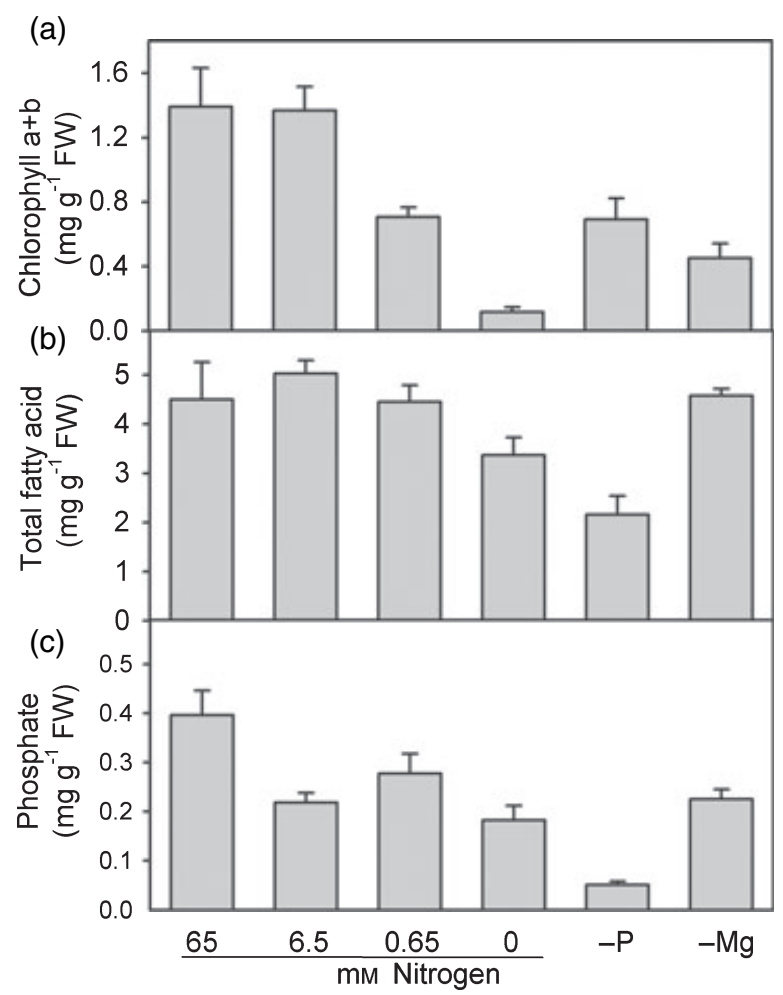

Figure 1. Nitrogen deficiency causes a decrease in chlorophyll and total fatty acids, but has a minor impact on phosphate content.

Arabidopsis WT plants were raised on MS medium for 2 weeks and subsequently grown on medium containing different amounts of $\mathrm{N}, \mathrm{P}$ or $\mathrm{Mg}$, for an additional time of 10 days. (a) Total chlorophyll was measured photometrically; (b) total fatty acids were measured by GC; (c) inorganic phosphate was quantified according to Itaya and Ui (1966). Note that growth at $6.5 \mathrm{~mm} \mathrm{~N}$ represents full nutrition (control).

was distorted and obscured by the starch granules. Taken together, while no effect on phosphate content was observed, $\mathrm{N}$ deficiency resulted in a decrease in fatty acid content and severe alterations in chloroplast ultrastructure.

Membrane lipid composition was determined in leaves during nutrient stress (Figure 3). Nitrogen deficiency results in a decrease in MGDG from approximately 50 to $35 \mathrm{~mol} \%$ with a concomitant increase in DGDG from 15 to $23 \mathrm{~mol} \%$ and in phospholipids from 35 to $42 \mathrm{~mol} \%$. Despite the alteration in galactolipid composition, fatty acid patterns of MGDG and DGDG were not altered in plants grown without $\mathrm{N}$ (Table 1). To address the question of whether $\mathrm{N}$ deprivation has a specific impact on the abundance of $\mathrm{N}$ containing glycerolipids (phosphatidylethanolamine, $\mathrm{PE}$; phosphatidylcholine, PC; phosphatidylserine, PS), root membrane lipid composition was analysed. Roots are enriched in phospholipids because they lack the galactolipid-rich thylakoid membranes of chloroplasts. Lipid composition in roots of plants grown without $\mathrm{N}$ did not change (Figure 3b). Therefore, in contrast to phosphate deprivation, $\mathrm{N}$ starvation does not result in the replacement of $\mathrm{N}$ containing glycerolipids with glycolipids. 

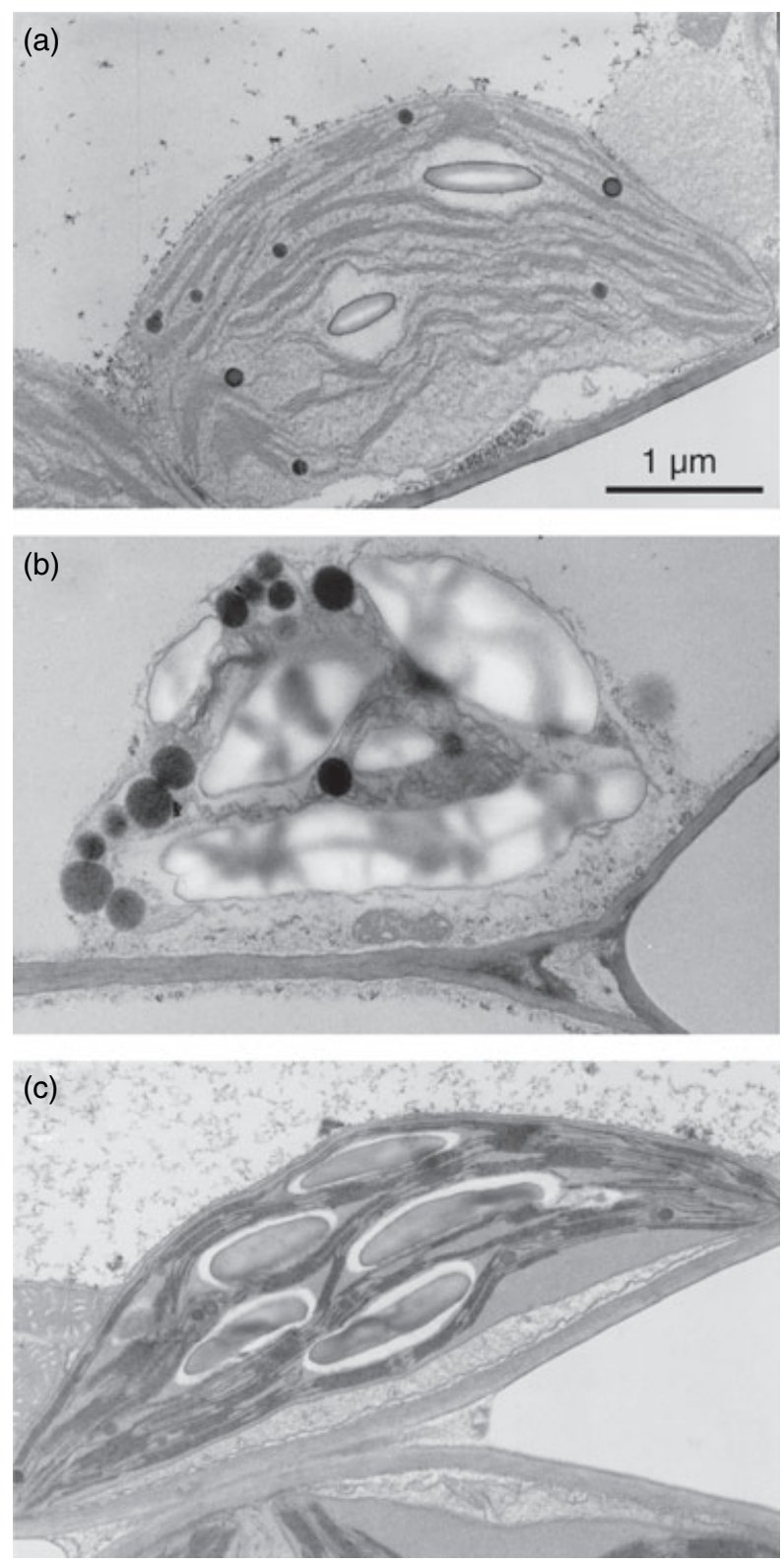

Figure 2. Nitrogen deficiency affects chloroplast ultrastructure in Arabidopsis.

Chloroplasts from leaf mesophyll cells of Arabidopsis WT plants raised in the absence of nitrogen $(-N)$ or phosphate $(-P)$ were analysed by electron microscopy. (a) Full nutrition; (b) plants deprived of $\mathrm{N}$; (c) plants deprived of phosphate. Bar $=1 \mu \mathrm{m}$.

Nitrogen deficiency causes a reduction in total fatty acids and in the ratio of MGDG to DGDG (Figures $1 \mathrm{~b}$ and $3 \mathrm{c}$ ). The Arabidopsis mutant nia1nia2, affected in nitrate reductase, is unable to convert nitrate into nitrite and thus shows an $\mathrm{N}$ deficient phenotype when grown with nitrate but in the absence of ammonia. The MGDG:DGDG ratio in nia1nia2 was reduced from 2.5 to 1.8 when plants were transferred from ammonia-containing to ammonia-free medium (Fig-
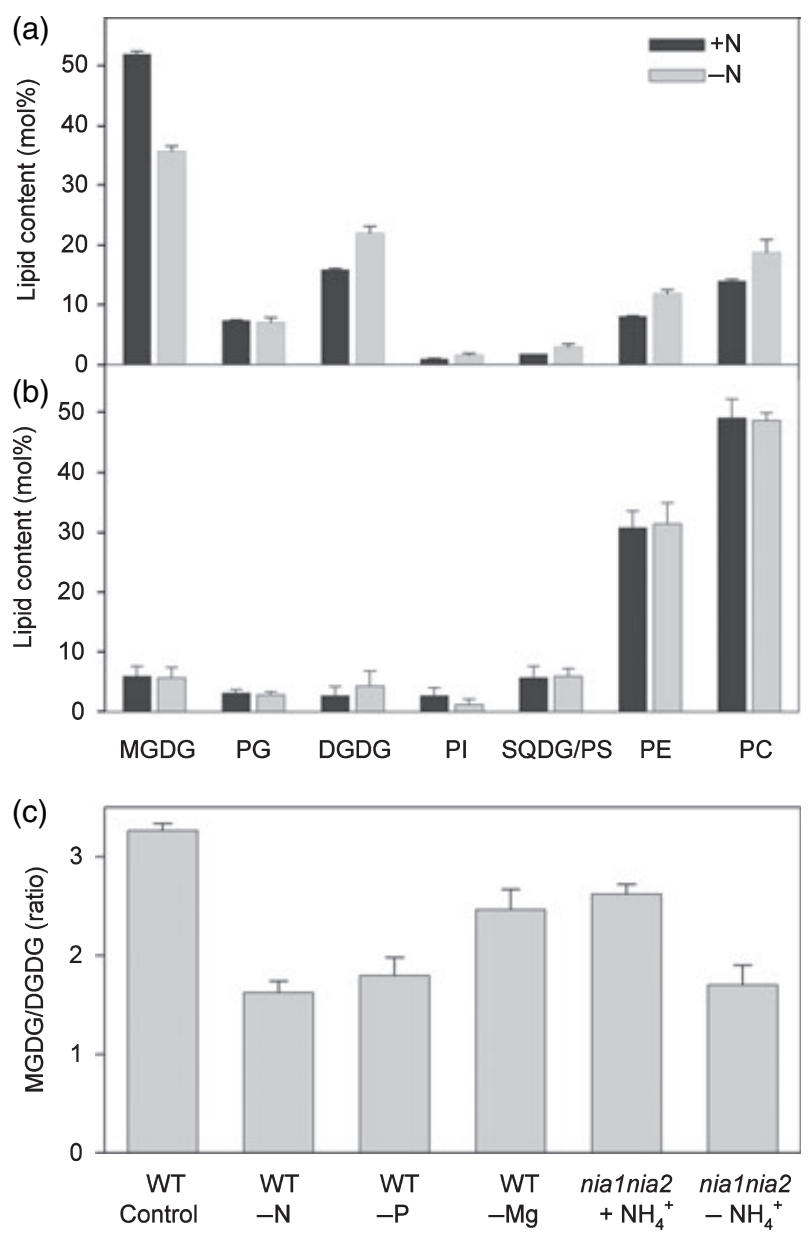

Figure 3. Lipid composition in leaves and roots during nitrogen deprivation. (a, b) Two-week-old Arabidopsis plants were transferred to medium with (black bars) or without (grey bars) nitrogen, and lipids from leaves (a) or roots (b) were extracted, separated by TLC and quantified by GC.

(c) The MGDG:DGDG ratio was determined in leaves of plants grown in the absence of nitrogen $(-\mathrm{N})$, phosphate $(-\mathrm{P})$ or magnesium $(-\mathrm{Mg})$. nia1nia2 mutant plants deficient in nitrate reductase were raised on medium with or without ammonia. Data represent mean \pm SD of three measurements. The experiment shown in $(a, b)$ was repeated with two different plant cultivations, with similar results.

ure 3c). Therefore the strong reduction in the MGDG:DGDG ratio observed in WT plants grown without $\mathrm{N}$ was corroborated by measuring galactolipids in nia1nia2 plants raised on nitrate. Wild-type plants grown in the absence of phosphate or Mg also showed a reduction in the MGDG:DGDG ratio, indicating that the preferential reduction in MGDG can originate from different nutrient-deficiency conditions.

\section{Alterations in galactolipid gene expression in nitrogen-deprived plants}

The changes in galactolipid composition observed during $\mathrm{N}$ deprivation prompted us to analyse the expression of genes involved in galactolipid synthesis. Expression of MGDG 
Table 1 Fatty acid composition of galactolipids after nitrogen deprivation

\begin{tabular}{|c|c|c|c|c|c|c|}
\hline & \multicolumn{3}{|c|}{ MGDG (mol\%) } & \multicolumn{3}{|c|}{ DGDG (mol\%) } \\
\hline & Control & $-\mathrm{N}$ & $-P$ & Control & $-\mathrm{N}$ & $-P$ \\
\hline $16: 0$ & 1.0 & 1.7 & $4.4^{*}$ & 10.0 & 9.3 & $26.0^{*}$ \\
\hline $16: 1$ & 0.7 & 0.5 & 1.6 & 0.2 & 0.2 & 2.9 \\
\hline $16: 2$ & 1.2 & 0.9 & 0.5 & 0.5 & 0.3 & 0.5 \\
\hline $16: 3$ & 33.5 & 33.3 & $26.4^{*}$ & 2.5 & 2.5 & 0.9 \\
\hline 18:0 & 0.2 & 0.3 & 1.1 & 0.7 & 0.8 & 3.2 \\
\hline 18:1 & 0.5 & 0.4 & 0.1 & 1.0 & 0.9 & 0.1 \\
\hline $18: 2$ & 2.5 & 3.4 & 2.8 & 4.6 & 8.4 & 6.7 \\
\hline $18: 3$ & 60.3 & 59.5 & 62.8 & 80.3 & 77.4 & $59.2^{*}$ \\
\hline
\end{tabular}

Galactolipids were isolated by TLC from leaves of plants raised without N or P. Fatty acid composition was analysed by GC of fatty acid methyl esters. Data represent means of three measurements and are derived from the plant cultivations (see Figure 3). SD was always below $<2 \mathrm{~mol} \%$. Values significantly different from control $(P<0.01)$ are marked with an asterisk.

(a)

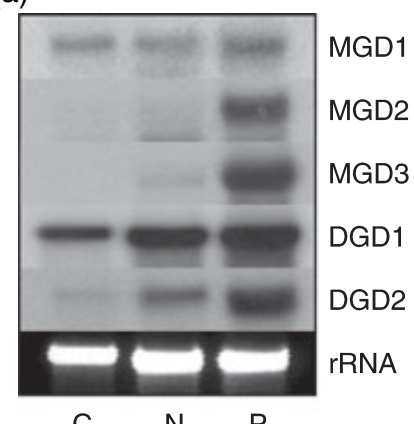

(b)

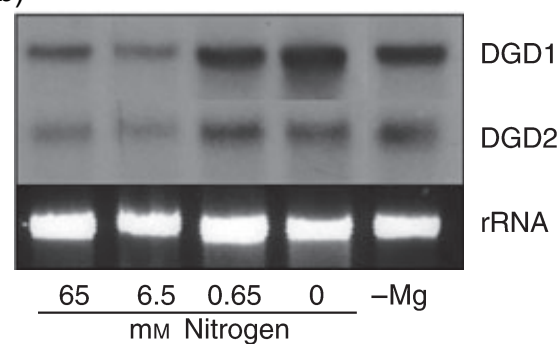

Figure 4. Expression of the two DGDG synthases DGD1 and DGD2 is increased during growth under $\mathrm{N}$ deficiency.

Two-week-old plants were grown on medium lacking nitrogen $(-\mathrm{N})$, phosphate $(-\mathrm{P})$ or magnesium $(-\mathrm{Mg})$. Northern blot analysis of total leaf RNA was carried out with different probes as indicated. The rRNA bands of the gel before blotting (stained with ethidium bromide) are shown as loading control. (a) Expression of MGD2, MGD3, DGD1 and DGD2 is upregulated under phosphate deprivation. $D G D 1$ and $D G D 2$ expression is increased under $\mathrm{N}$ deficiency.

(b) Northern analysis of plants derived from a second, independent plant cultivation demonstrated that the stimulation of DGD1 and DGD2 expression depends on the $\mathrm{N}$ concentration in the medium.

synthases (MGD1, MGD2, MGD3) and DGDG synthases (DGD1, DGD2) was recorded by Northern blot. In accordance with previous reports, phosphate deprivation resulted in

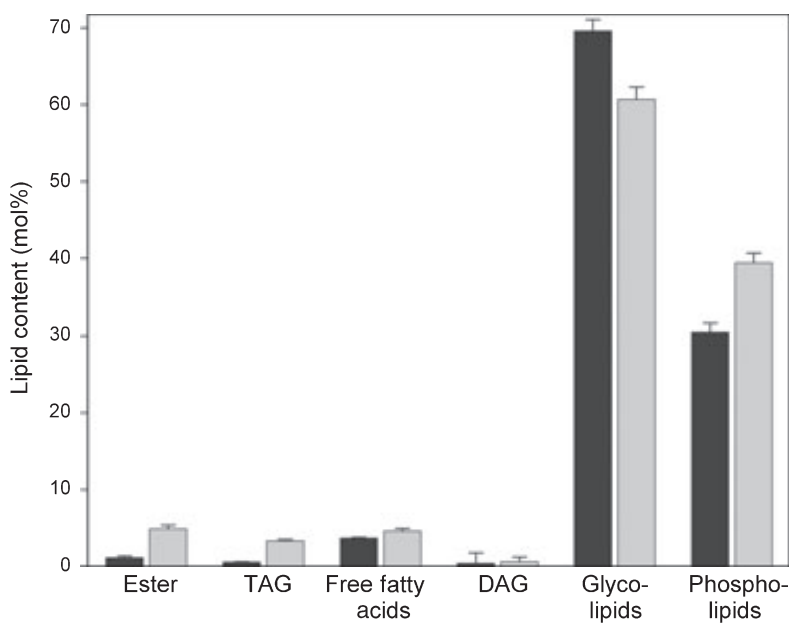

Figure 5. Accumulation of non-polar lipids during nitrogen starvation. Non-polar lipids were isolated from leaves of plants grown in the presence (black bars) or absence (grey bars) of nitrogen. Lipids were separated by TLC and quantified by GC. The relative amounts of glycolipids (MGDG, DGDG SQDG) and phospholipids (PG, PI, PC, PE) in the polar lipid fraction was calculated from data presented in Figure 3. Values represent mean $\pm \mathrm{SD}$ of three measurements. The experiment was repeated with lipids derived from one additional plant cultivation, with the same results.

stimulation of the expression of $M G D 2, M G D 3, D G D 1$ and DGD2 (Awai et al., 2001; Kelly and Dörmann, 2002; Kelly et al., 2003). Expression of $M G D 2$ and $M G D 3$ during $\mathrm{N}$ deficiency was not altered (Figure 4a). However, expression of $D G D 1$ and $D G D 2$ was markedly increased, and this increase depended on the concentration of $\mathrm{N}$ in the growth medium (Figure 4b). Magnesium deficiency also resulted in an increase in DGD1 and DGD2 expression.

\section{Accumulation of triacylglycerols, free fatty acids and fatty acid phytyl esters}

To study the fate of acyl groups derived from MGDG turnover during $\mathrm{N}$ deprivation, non-polar leaf lipids were separated by TLC and quantified by GC of fatty acid methyl esters (Figure 5). In accordance with the reduction in MGDG content (Figure 3), the relative amount of glycolipids in leaves decreased from 69 to $60 \mathrm{~mol} \%$ during $\mathrm{N}$ deprivation. This decrease was accompanied by an increase in phospholipids and in non-polar lipids, in particular triacylglycerols, free fatty acids and lipid esters. In Arabidopsis, MGDG is rich in hexadecatrienoic acid (16:3) derived from the chloroplastlocalized pathway of lipid synthesis. Thus determining the fatty acid composition of non-polar lipid classes was expected to reveal the fate of MGDG-derived fatty acids. High amounts of 16:3 were detected in the lipid ester fraction, suggesting that a large amount of fatty acid derived from MGDG breakdown was converted into lipid esters (Table 2).

Chlorophyll degradation during $\mathrm{N}$ deprivation (Figure 1) results in the release of free phytol. To address the question 
Table 2 Fatty acid composition of non-polar lipids after nitrogen deprivation

\begin{tabular}{|c|c|c|c|c|c|c|c|c|}
\hline & \multicolumn{2}{|c|}{ Diacylglycerol (mol\%) } & \multicolumn{2}{|c|}{ Free fatty acid (mol\%) } & \multicolumn{2}{|c|}{ Triacylglycerol (mol\%) } & \multicolumn{2}{|c|}{ Lipid ester (mol\%) } \\
\hline & $\mathrm{N}+$ & $\mathrm{N}-$ & $\mathrm{N}+$ & $\mathrm{N}-$ & $\mathrm{N}+$ & $\mathrm{N}-$ & $\mathrm{N}+$ & $\mathrm{N}-$ \\
\hline 16:0 & $60.2 \pm 4.2$ & $70.3 \pm 6.5$ & $47.6 \pm 3.8$ & $45.3 \pm 0.7$ & $52.9 \pm 0.6$ & $75.6 \pm 3.3^{*}$ & $62.9 \pm 2.9$ & $48.9 \pm 2.3^{*}$ \\
\hline $16: 1$ & $4.9 \pm 0.6$ & $1.7 \pm 0.6^{*}$ & $2.8 \pm 1.0$ & $0.7 \pm 0.2$ & $3.8 \pm 0.8$ & $0.8 \pm 0.4^{*}$ & $3.2 \pm 1.3$ & $2.7 \pm 1.2$ \\
\hline $16: 2$ & $7.9 \pm 1.0$ & $7.0 \pm 2.3$ & $1.1 \pm 0.5$ & $0.5 \pm 0.2$ & $5.0 \pm 0.8$ & $3.6 \pm 1.7$ & $6.8 \pm 2.7$ & $6.7 \pm 2.6$ \\
\hline $16: 3$ & $2.7 \pm 1.0$ & $1.3 \pm 0.2$ & $1.2 \pm 0.3$ & $0.4 \pm 0.2$ & $7.6 \pm 1.7$ & $1.1 \pm 0.1^{*}$ & $5.5 \pm 2.5$ & $19.4 \pm 2.5^{*}$ \\
\hline 18:0 & $16.7 \pm 0.3$ & $14.6 \pm 0.5^{*}$ & $36.3 \pm 4.2$ & $52.6 \pm 0.6^{*}$ & $22.7 \pm 3.4$ & $14.5 \pm 2.2$ & $16.0 \pm 3.4$ & $5.2 \pm 2.1^{*}$ \\
\hline 18:1 & $1.1 \pm 0.3$ & $0.9 \pm 0.4$ & $3.9 \pm 0.2$ & $0.4 \pm 0.2$ & $1.3 \pm 0.4$ & $0.2 \pm 0.0$ & $3.2 \pm 1.7$ & $1.3 \pm 0.2$ \\
\hline $18: 2$ & $5.4 \pm 3.3$ & $0.8 \pm 0.4$ & $2.6 \pm 0.4$ & $0.1 \pm 0.0$ & $1.7 \pm 0.5$ & $0.8 \pm 0.3$ & $0.4 \pm 0.2$ & $6.7 \pm 3.2^{*}$ \\
\hline $18: 3$ & $1.9 \pm 0.1$ & $2.8 \pm 1.4^{*}$ & $4.1 \pm 1.3$ & $0.2 \pm 0.1$ & $6.0 \pm 0.9$ & $3.5 \pm 0.4^{*}$ & $1.8 \pm 0.6$ & $10.2 \pm 1.0^{*}$ \\
\hline
\end{tabular}

Non-polar lipids were isolated by TLC from leaves of plants grown with or without N. Fatty acids of individual lipids were determined by GC of methyl esters. Data represent means $\pm \mathrm{SD}$ of three measurements derived from the plant cultivations (see Figure 5). Values significantly different from control $(P \leq 0.05)$ are marked with an asterisk.
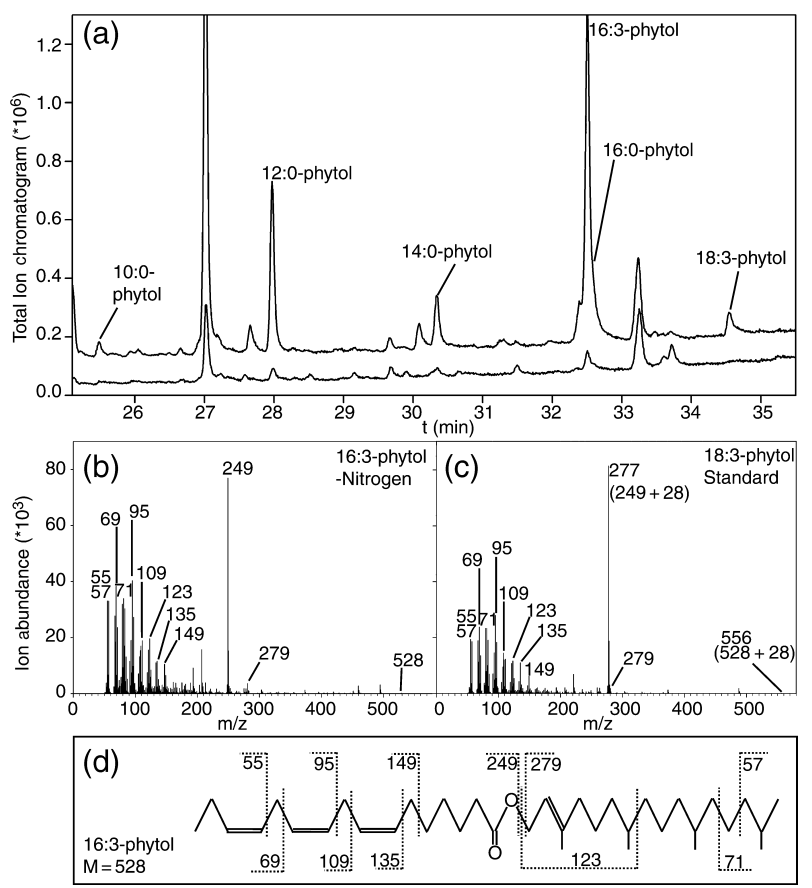

Figure 6. Increase in FAPE content after nitrogen deprivation.

Lipid esters isolated by TLC from leaves of Arabidopsis WT plants after N deprivation were identified by GC-MS.

(a) Total ion chromatograms of plants grown in the presence (bottom) or absence (top) of $\mathrm{N}$. Note that 16:0-phytol has a retention time very similar to 16:3-phytol, forming a shoulder on the right side of 16:3-phytol.

(b) Mass spectrum of plant 16:3-phytol (peak at 32.5 min of $-\mathrm{N}$ chromatogram).

(c) Mass spectrum of synthetic 18:3 standard.

(d) Fragmentation pattern of 16:3-phytol.

whether phytol might be incorporated into the lipid ester fraction, lipid esters were isolated by TLC and cleaved by transmethylation. After silylation, GC-MS analysis revealed the presence of phytol in lipid esters (data not shown). To determine the composition of acyl groups, lipid esters were isolated by TLC and analysed by GC-MS without derivatization (Figure 6). A large peak was detected in the chromato- gram of $\mathrm{N}$-deprived plants that was barely detectable in control leaves (Figure 6a). The fragmentation pattern of this peak was consistent with the structure of hexadecatrienoic acid phytyl ester (16:3-phytol). Additional lipid esters were identified with mass spectra corresponding to saturated, medium and long-chain FAPEs (10:0-phytol, 12:0-phytol, 14:0-phytol, 16:0-phytol). FAPE standards were chemically synthesized and their retention time and mass spectra analysed by GC-MS. Because 16:3 was not commercially available, the mass spectrum of the putative 16:3-phytol peak was compared with that of a synthetic $\alpha$-linolenic acid phytyl ester (18:3-phytol; Figure 6c). The two mass spectra were almost identical, with the exception of two fragments derived from the fatty acid and the molecular mass ion, which were larger by $28\left(\mathrm{C}_{2} \mathrm{H}_{2}\right)$ in 18:3-phytol than in 16:3-phytol. Therefore the predominant fatty acid alcohol ester accumulating in $\mathrm{N}$-deprived plants was identified as 16:3-phytol.

\section{Localization of FAPEs to plastoglobules and thylakoids of chloroplasts}

The fact that the two constituents of FAPEs, fatty acids and phytol, are derived from galactolipid and chlorophyll catabolism, respectively, suggested that these lipid esters localize to chloroplasts. Furthermore, the increase in number and size of plastoglobules after $\mathrm{N}$ deprivation (Figure $2 \mathrm{~b}$ ) indicated that these lipid structures represent a potential site of FAPE deposition. To determine the subcellular localization of phytyl esters experimentally, chloroplasts were isolated from Arabidopsis plants grown on soil. After chloroplast rupture, fractions enriched in plastoglobules, envelope membranes and thylakoids were separated by sucrose-density centrifugation. Western blots for marker proteins were carried out to confirm the identity of the chloroplast fractions (Vidi et al., 2006). Total phytyl esters and total fatty acids were measured by GC-MS and GC, respectively, and the ratio of total FAPEs to total fatty acids was calculated (Figure 7). The largest amount of phytyl 


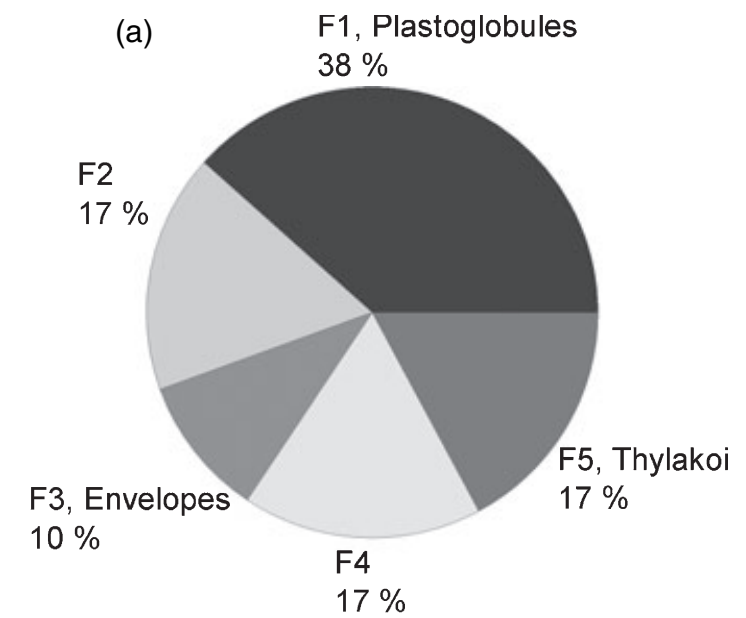

(b)

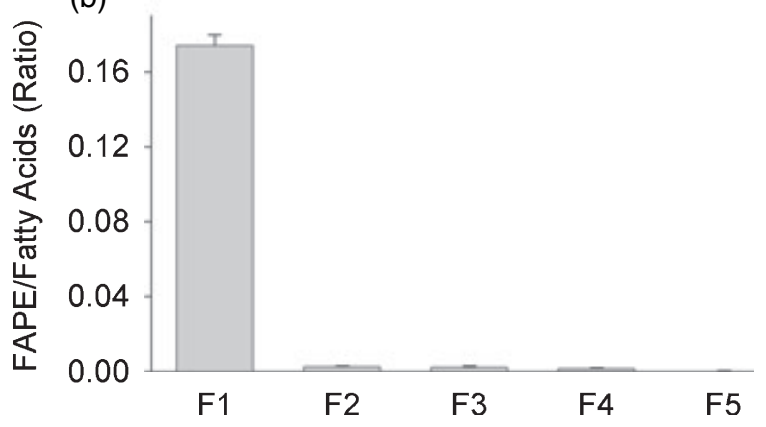

Figure 7. FAPEs localize to plastoglobules and thylakoids of chloroplasts. Chloroplasts isolated from soil-grown Arabidopsis plants were ruptured and sub-plastidial fractions obtained by sucrose step-gradient centrifugation. The content of the gradient fractions was confirmed by Western analysis (Vidi et al., 2006) using antibodies raised to marker proteins and the fractions pooled accordingly. Fractions F1 and F2 contained mostly plastoglobules; F3 was enriched in envelopes; F4 and F5 (green) contained envelope and thylakoid membranes. FAPEs were measured by GC-MS.

(a) Total FAPEs (\%) in the different subplastidial pooled fractions.

(b) Ratio of FAPEs (nmol) per total fatty acid (nmol).

The data presented are derived from one of two independent chloroplastisolation experiments which gave very similar results.

esters was associated with the pooled fraction F1 (plastoglobules; Figure 7a). Fractions F1 (plastoglobules) and F2 (mostly plastoglobules) contained $>50 \%$ of total fatty acid phytyl esters of the chloroplast. Fraction F3 (envelopes and thylakoids) contained about $10 \%$, and the last two fractions (F4, some envelopes and thylakoids; F5, mostly thylakoids) about $34 \%$ of FAPE. The ratio of phytyl esters to total fatty acids (nmol per nmol) was highest in plastoglobules (F1; Figure $7 \mathrm{~b}$ ). A ratio of 0.17 indicates that about $17 \%$ of total fatty acids were bound to phytyl esters, therefore fatty acid phytyl esters represent a major lipid class in plastoglobules.

Fatty acid phytyl esters in Arabidopsis mutants affected in lipid synthesis

Quantification by GC-MS revealed that the total amount of phytyl esters in Arabidopsis increased from 5 to approxi- mately $200 \mathrm{nmol} \mathrm{g}^{-1} \mathrm{FW}$ during $\mathrm{N}$ deprivation (Figure 8a). 16:3-phytol constituted about $50 \%$ of phytyl esters, the remainder being saturated medium-chain FAPEs (10:0, 12:0, 14:0) and 16:0-phytol (Figure 8c). Different Arabidopsis mutants affected in chloroplast lipid metabolism were employed to study the biochemical pathway of FAPE synthesis. Because 10:0, 12:0 and 14:0 are intermediates of plastidial fatty acid de novo synthesis, medium-chain fatty acids in phytyl esters might be directly derived form acyl-acyl carrier protein (acyl-ACP) by thioesterases prior to incorporation into phytyl esters. The acyl-ACP thioesterase FatB in Arabidopsis is specific for 16:0 and medium-chain acyl groups (Bonaventure et al., 2003), and thus represents a possible enzymatic step in the pathway of FAPE synthesis. Measurements of FAPEs in the Arabidopsis fat $B$ mutant (Bonaventure et al., 2003) revealed no differences in the total amounts or composition of phytyl esters (Figure 8c). Thus hydrolysis of acyl-ACPs by the FatB thioesterase is not a prerequisite, but it is possible that acyl-ACPs serve directly as substrates for phytyl ester synthesis.

Because 16:3 is highly abundant in MGDG, this galactolipid represents a potential precursor for 16:3-phytol production. MGD1 is the major MGDG synthase in Arabidopsis, and in the corresponding mgd1 mutant the amount of MGDG is reduced to about $50 \%$ of WT (Awai et al., 2001; Jarvis et al., 2000). FAPE measurement in the $m g d 1$ mutant revealed that the amount of 16:3-phytol was not changed, indicating that the decrease in MGDG content was not limiting for 16:3phytol synthesis (Figure 8c). However, the block in MGDG synthesis in mgd1 is only partial, and it is possible that a more severe reduction in MGDG content affects phytyl ester synthesis.

To address the question whether 16:3 in phytyl esters can be replaced with other unsaturated fatty acids, we analysed a 16:3-free plant, act1. The act1 mutant contains only negligible amounts of 16:3 due to a block in the plastidlocalized glycerol-3-phosphate acyltransferase (Kunst et al., 1988). No 16:3-phytol was detected in act1 after $\mathrm{N}$ deprivation, and the total amount of FAPEs was reduced (Figure $8 a, c)$. The fact that the amounts of $18: 3$ or other unsaturated fatty acids in the FAPE pool of act1 did not increase suggests that 16:3-phytol synthesis is a highly specific process in Arabidopsis.

\section{Distribution of unsaturated fatty acids in phytyl esters of different plant species}

In contrast to Arabidopsis, which contains high amounts of $16: 3$ ('16:3' plant), other species have lost the capacity to synthesize this fatty acid and therefore contain $\alpha$-linolenic acid (18:3) as the only triunsaturated fatty acid ('18:3' plants). The high abundance of $16: 3$ accompanied by the absence of 18:3 in phytyl esters of Arabidopsis prompted us to analyse the distribution of unsaturated acyl groups in phytyl esters in 
Figure 8. FAPE composition in Arabidopsis and in additional plant species during nitrogen deprivation.

Plants raised under full nutrition were transferred to $\mathrm{N}$-free medium and leaves were harvested for FAPE measurement by GC-MS. Data represent mean \pm SD of three measurements of plants derived from two $\mathrm{N}$-starvation experiments. (a) Total amounts of FAPEs in Arabidopsis mutants.

(b) Phytyl esters in different plant species (c) FAPE composition in Arabidopsis mutants (d) FAPE composition in different plant species. A.t., Arabidopsis thaliana; S.t., potato; C.p., pumpkin; O.s., rice; L.j., Lotus japonicus.
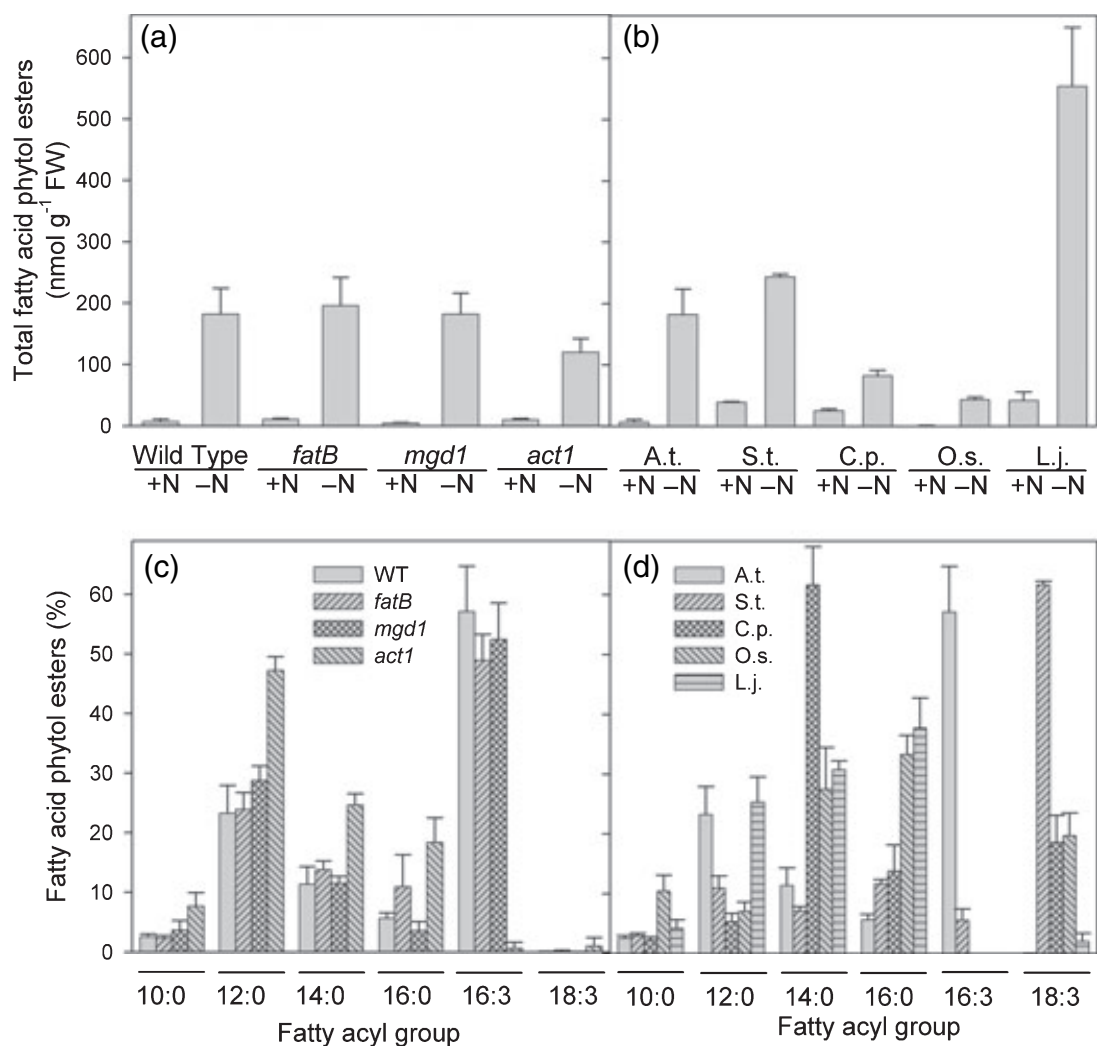

different plants, including $16: 3$ and $18: 3$ species. In addition to Arabidopsis, we selected one additional 16:3 species (potato) and three 18:3 plants (pumpkin, rice and Lotus). In all five species, $\mathrm{N}$ deprivation led to a drastic increase in phytyl ester content to up to $500 \mathrm{nmol} \mathrm{g}^{-1} \mathrm{FW}$ (Figure 8b). The phytyl ester pool of all species contained medium-chain acyl groups (10:0, 12:0, 14:0) and 16:0 after $N$ deprivation. However, large differences were found in the content of unsaturated acyl groups. The major unsaturated fatty acids in phytyl esters were 16:3 or 18:3; only very low amounts of oleic acid (18:1) and linoleic acid (18:2) were found (data not shown). In contrast to Arabidopsis ( $>50 \%$ 16:3-phytol), potato contained only approximately 10\% 16:3-phytol and $60 \%$ 18:3-phytol. All three 18:3 species were devoid of $16: 3$ phytol. The amounts of 18:3-phytol were approximately $20 \%$ in pumpkin and rice, and only approximately $2 \%$ in Lotus. In the latter three species, considerable amounts of mediumchain and 16:0 acyl groups accumulated in phytyl esters. Therefore FAPE synthesis appears to occur in all higher plants, but the acyl group composition shows strong variations in the different species.

\section{Discussion}

Nitrogen deficiency leads to reprogramming of the cellular metabolism because the synthesis of numerous compounds depends on $\mathrm{N}$ assimilation. Previous studies demonstrated that $\mathrm{N}$ deficiency affects the abundance of chlorophyll and thylakoid membranes and results in increased plastoglobule size in Euglena, rice, sugar beet and cotton (García-Ferris et al., 1996; Kutík et al., 1995; Laza et al., 1993; Malavolta et al., 2004). During $\mathrm{N}$ deprivation in Arabidopsis, a strong decrease in MGDG content, with a concomitant increase in DGDG, was observed (Figure 3). A decrease in total galactolipid content and a decrease in the MGDG:DGDG ratio on $\mathrm{N}$ starvation have been described so far only for algae (López Alonso et al., 2000; Mock and Kroon, 2002). A decrease in the MGDG:DGDG ratio was also observed during Mg deprivation (Figure 3), suggesting that the reduction in photosynthetic units during nutrient stress affects the abundance of thylakoid membranes with a decrease in the MGDG:DGDG ratio. The specific reduction in MGDG during $\mathrm{N}$ deficiency presumably stabilizes thylakoid membranes because, in contrast to DGDG, which forms bilayers, MGDG is the only non-bilayer-forming lipid in chloroplasts (Webb and Green, 1991).

The fatty acid composition of MGDG and DGDG remained almost unchanged during $\mathrm{N}$ starvation (Table 1). In contrast, phosphate deprivation resulted in an increase of 16:0 in DGDG and a decrease of 16:3 in MGDG (Härtel et al., 2000; Kelly et al., 2003), which might be attributed to the increased expression of the MGDG synthases MGD2 and MGD3 (Awai et al., 2001). Therefore phosphate deprivation results in a net increase in galactolipid synthesis with the accumulation of DGDG with a distinct fatty acid pattern. Under $\mathrm{N}$ deprivation, however, MGD2 and MGD3 expression remained un- 
changed, which might explain why MGDG and DGDG fatty acid compositions were not altered. Thus $\mathrm{N}$ deprivation results in the conversion of a fraction of the already existing MGDG to DGDG. Regulation of DGD1 and DGD2 expression under $\mathrm{N}$ deprivation is independent of the phosphate status of the plants (Figure 1). Furthermore, the fact that DGD1 and $D G D 2$, but not $M G D 2$ and $M G D 3$ expression are stimulated during $\mathrm{N}$ deprivation suggests that regulation is different from phosphate deprivation, which results in the induction of all four genes (Awai et al., 2001; Kelly and Dörmann, 2002; Kelly et al., 2003). The replacement of phospholipids with glycolipids during phosphate deprivation leads to the remobilization of phosphate from the membranes. It has been estimated that one-third of organic phosphate is bound to phospholipids (Poirier et al., 1991), therefore the remobilization of phosphate from membranes is important for phosphate homeostasis. In contrast, $\mathrm{N}$ deprivation did not affect the amounts of $\mathrm{N}$-containing glycerolipids (PC, PE and PS). The amount of $N$ in PC, PE and PS is low (about 1.7 $\mu \mathrm{mol} \mathrm{N} \mathrm{g}{ }^{-1} \mathrm{FW}$ considering $25 \%$ total PC, PE, PS content in leaves; Figure 1 and 3). Considerable amounts of $\mathrm{N}$ are found in chlorophyll (approximately $6.0 \mu \mathrm{mol} \mathrm{N} \mathrm{g}{ }^{-1} \mathrm{FW}$; Figure 1); free amino acids $\left(0.3 \mu \mathrm{mol} \mathrm{g}^{-1} \mathrm{FW}\right.$; calculated from Carrari et al., 2005); and protein-bound amino acids $\left(11 \mathrm{mg}\right.$ protein $\mathrm{g}^{-1} \mathrm{FW}$, equivalent to approximately $100 \mu \mathrm{mol} \mathrm{N} \mathrm{g}{ }^{-1} \mathrm{FW}$ ). The low $\mathrm{N}$ content in glycerolipids might explain why $\mathrm{N}$ deprivation does not affect the amounts of PC, PE and PS, but rather results in the remobilization of $\mathrm{N}$ from protein-bound amino acids.

A strong increase in triacylglycerol, free fatty acids and lipid esters was observed during $\mathrm{N}$ deprivation (Figure 5). Similarly, protoplastation or senescence also resulted in a strong increase in non-polar lipid synthesis (Browse et al., 1988; Kaup et al., 2002). Presumably, fatty acids derived from galactolipid breakdown are not immediately degraded but accumulate in non-polar lipids, in particular lipid esters (Figure 9). FAPEs were previously found in dinoflagellates (Cranwell et al., 1985, 1990), mosses (Buchanan et al., 1996; Gellerman et al., 1975) and bacteria (Rontani et al., 1999), but their function remained unknown. Furthermore, phytyl esters have been identified in higher plants including Acer platanoides, parsley, Phaseolus, grasses, and some Amazonian species (Anderson et al., 1984; Csupor, 1971; Gellerman et al., 1975; Peisker et al., 1989; Pereira et al., 2002). Phytyl esters accumulate in the Arabidopsis chilling sensitive mutant 1 (Patterson et al., 1993). The identification of phytyl esters in WT Arabidopsis, and its drastic increase during N deprivation and senescence (Figure 6; Ischebeck et al., 2006) clearly demonstrate that FAPEs represent a class of stressregulated higher plant lipids. The phytol moiety of FAPEs is presumably derived from chlorophyll degradation. The amount of tocopherol, another phytol-dependent lipid, also increases in leaves under $\mathrm{N}$ limitation $(11.5 \pm 1.0$ and $22.7 \pm 3.0 \mu \mathrm{g} \mathrm{g}^{-1} \mathrm{FW}$ for $+\mathrm{N}$ and $-\mathrm{N}$ conditions, respect-

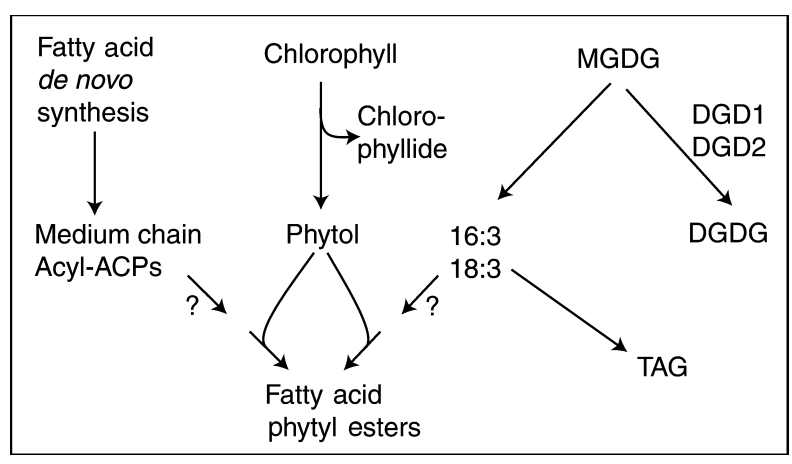

Figure 9. Lipid changes observed during nitrogen deprivation. During $\mathrm{N}$ deprivation, degradation of MGDG results in the release of free fatty acids, in particular 16:3 and 18:3. Additional DGDG is synthesized from MGDG after induction of $D G D 1$ and DGD2. Fatty acids released from MGDG are incorporated into triacylglycerol, or esterified to phytol which is released during chlorophyll degradation. Furthermore, medium-chain acyl-ACPs could serve as precursors for FAPE synthesis. However, the nature of the substrates and the mechanism of FAPE synthesis is unknown.

ively). Previous studies have already indicated that phytol from chlorophyll degradation might be employed for tocopherol synthesis (Ischebeck et al., 2006; Peisker et al., 1989; Rise et al., 1989; Valentin et al., 2006).

FAPEs were localized to chloroplasts, and were particularly enriched in plastoglobules (Figure 7). In addition to plants raised on soil (Figure 7), chloroplasts were also isolated from leaves of $\mathrm{N}$-deprived plants. However, due to the extremely low yield, chloroplasts from $\mathrm{N}$-starved plants had to be prepared by protoplastation, which might affect lipid composition (Browse et al., 1988). Very similar results were obtained, as presented in Figure 7: the majority of FAPEs in chloroplasts of $\mathrm{N}$-deprived plants localized to plastoglobules and thylakoids (data not shown). To assess the distribution of membrane lipids and non-polar lipids, chloroplast fractions were also analysed by TLC. In agreement with previous studies (Tevini and Steinmüller, 1985), high proportions of non-polar lipids and only low amounts of galactolipids were detected in plastoglobules. In contrast, galactolipids were predominant in thylakoids (data not shown). Interestingly, tocopherol cyclase, a key enzyme of tocopherol synthesis, as well as high amounts of tocopherol, were localized to plastoglobules of chloroplasts (Austin et al., 2006; Vidi et al., 2006; Ytterberg et al., 2006). Therefore FAPEs and tocopherol both localize to plastoglobules, where they might accumulate during senescence or abiotic stress. FAPEs and tocopherol might represent a transient sink for the deposition of fatty acids and phytol, which, in their free form, might destabilize the bilayer membrane of thylakoids due to their detergent-like characteristics.

The mechanism of FAPE production in higher plants remains unclear. All plant species analysed in this study accumulate saturated, medium-chain acyl groups (10:0, $12: 0,14: 0)$ and $16: 0$ in phytyl esters during $N$ deprivation, 
suggesting that they might be derived from plastidial fatty acid synthesis (Figure 9). In addition, unsaturated acyl groups, in particular $16: 3$ or $18: 3$, were detected in the phytyl ester fraction. Only low amounts of 18:3-phytol accumulate in the Arabidopsis act1 mutant, although MGDG in act1 contains large amounts of $18: 3$ instead of $16: 3$. Therefore the incorporation of 16:3 into phytyl esters is a highly specific process in Arabidopsis. Further evidence for the high specificity of phytyl ester synthesis for unsaturated acyl groups came from the analysis of additional species including 16:3 and 18:3 plants. Comparison of Arabidopsis and potato, two 16:3 plants, showed that only in Arabidopsis, $16: 3$ is predominant in phytyl esters, whereas 18:3phytol is most abundant in potato. Potato contains even more 18:3-phytol than the authentic 18:3 plants pumpkin, rice or Lotus, the latter being basically devoid of 18:3-phytol. These results suggest that two pathways of FAPE synthesis might exist in plants: one specific for medium-chain and 16:0 acyl groups derived from plastidial fatty acid de novo synthesis; and a second pathway that is highly specific for 16:3 or 18:3 in the different plant species (Figure 9). Our data clearly demonstrate that during $\mathrm{N}$ deprivation galactolipids are subject to lipid turnover, and the acyl groups released in this process are to a large extent incorporated into FAPEs. Furthermore, these processes depend on the activity of specific enzymes present in different plant species. The genes encoding enzymes of FAPE synthesis and their functions remain unknown, and will be the focus of future studies.

\section{Experimental procedures}

\section{Plants and growth conditions}

Arabidopsis thaliana plants (ecotype Columbia) were grown on Murashige and Skoog (1962) medium (MS) with $2 \%$ (w/v) sucrose, $20 \mathrm{~mm}$ MES-KOH pH 5.6, at $120 \mu \mathrm{mol} \mathrm{m}{ }^{-2} \mathrm{sec}^{-1}$ light ( $16 \mathrm{~h}$ per day). Arabidopsis mutants were as described elsewhere ( $f a t B$, Bonaventure et al., 2003; mgd1, Jarvis et al., 2000; act1, Kunst et al., 1988). After 2 weeks, plants were transferred to synthetic media containing: $0.8 \%$ agarose, $1 \%$ sucrose, $2.5 \mathrm{~mm} \mathrm{KNO}_{3}, 1 \mathrm{~mm} \mathrm{MgSO}, 1 \mathrm{~mm}$

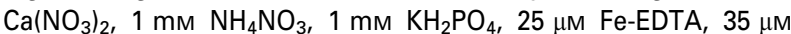
$\mathrm{H}_{3} \mathrm{BO}_{3}, 7 \mu \mathrm{m} \mathrm{MnCl}, 0.25 \mu \mathrm{m} \mathrm{CuSO}, 0.5 \mu \mathrm{m} \mathrm{ZnSO}{ }_{4}, 0.1 \mu \mathrm{m} \mathrm{Na}_{2} \mathrm{MoO}_{4}$, $5 \mu \mathrm{M} \mathrm{NaCl}, 5 \mathrm{~nm} \mathrm{CoCl}_{2}$ (Estelle and Somerville, 1987). For phosphate deprivation, $\mathrm{KH}_{2} \mathrm{PO}_{4}$ was omitted from the medium. Media for $\mathrm{N}$-deprivation experiments were based on synthetic medium with $0 \mathrm{~mm} \mathrm{~N}\left[0 \mathrm{~mm} \mathrm{Ca}\left(\mathrm{NO}_{3}\right)_{2}, 1 \mathrm{~mm} \mathrm{CaCl}, 0 \mathrm{~mm} \mathrm{NH} \mathrm{NO}_{3}, 0 \mathrm{~mm} \mathrm{KNO}{ }_{3}\right.$, $2.5 \mathrm{~mm} \mathrm{KCl}, 0.65 \mathrm{~mm} \mathrm{~N}\left[0.1 \mathrm{~mm} \mathrm{Ca}\left(\mathrm{NO}_{3}\right)_{2}, 0.9 \mathrm{~mm} \mathrm{CaCl}, 0.1 \mathrm{~mm}\right.$ $\mathrm{NH}_{4} \mathrm{NO}_{3}, 0.25 \mathrm{~mm} \mathrm{KNO}, 2.25 \mathrm{~mm} \mathrm{KCl}$ ], $6.5 \mathrm{~mm} \mathrm{~N}$ (complete synthetic medium, see above) or $65 \mathrm{~mm} \mathrm{~N}\left[10 \mathrm{~mm} \mathrm{Ca}\left(\mathrm{NO}_{3}\right)_{2}, 0 \mathrm{~mm}\right.$ $\left.\mathrm{CaCl}_{2}, 10 \mathrm{~mm} \mathrm{NH}_{4} \mathrm{NO}_{3}, 25 \mathrm{~mm} \mathrm{KNO}_{3}, 0 \mathrm{~mm} \mathrm{KCl}\right]$.

The nia1nia2 double mutant $\left(\mathrm{G}^{\prime} 4-3\right)$ defective in the two nitrate reductase genes NIA1 and NIA2 (Wilkinson and Crawford, 1991, 1993; Nottingham Arabidopsis Seed Centre, UK) was germinated on MS medium, and 3 weeks later transferred to ammonia-containing medium [synthetic medium with $0 \mathrm{~mm} \mathrm{Ca}\left(\mathrm{NO}_{3}\right)_{2}, 1 \mathrm{mM} \mathrm{CaCl}_{2}$, $2.5 \mathrm{~mm} \mathrm{NH}_{4} \mathrm{NO}_{3}, 0 \mathrm{~mm} \mathrm{KNO}{ }_{3} 1 \mathrm{~mm} \mathrm{KCl}$ ] or ammonia-free medium [synthetic medium with $0 \mathrm{~mm} \mathrm{Ca}\left(\mathrm{NO}_{3}\right)_{2}, 1 \mathrm{~mm} \mathrm{CaCl}_{2}, 0 \mathrm{mM} \mathrm{NH}_{4} \mathrm{NO}_{3}$,
$5 \mathrm{~mm} \mathrm{KNO}_{3}, 2.5 \mathrm{~mm} \mathrm{KCl]}$. The medium for nia1nia2 was adjusted to $\mathrm{pH} 6.5$ because nia1nia2 growth is strongly affected at $\mathrm{pH}<6.0$ (Wang et al., 2004).

Plants of Lotus japonicus were germinated on MS medium, and after 3 weeks transferred to $\mathrm{N}$-free medium (see above). Potato (Solanum tuberosum Désirée), rice (Oryza sativa) and pumpkin (Cucurbita pepo Gelber Zentner) plants were raised in the glasshouse on sand fertilized with complete nutrient solution (Pacovsky and Fuller, 1988), and after 5 weeks transferred to pots watered with $\mathrm{N}$-deficient solution. Leaf samples were taken 4-8 weeks later, when plants showed clear symptoms of $\mathrm{N}$ deprivation (reduced growth, yellowish leaves).

\section{Measurements of lipids, chlorophyll and phosphate}

Total fatty acids in leaves were transmethylated and quantified by GC-flame ionization detection (FID) using pentadecanoic acid (15:0) as internal standard according to Browse et al. (1986). Lipids were extracted from frozen leaves with 2 vol chloroform/methanol/formic acid (1:1:0.1) and $1 \mathrm{vol} 1 \mathrm{~m} \mathrm{KCl}, 0.2 \mathrm{M} \mathrm{H}_{3} \mathrm{PO}_{4}$. Membrane lipids were separated by TLC (Dörmann et al., 1995a,b). Non-polar lipids were first purified by chromatography on silica columns (Kieselgel 60; Merck http://www.vwr.com) developed with chloroform/methanol (2:1) prior to separation by TLC with hexane/diethylether/acetic acid (85:15:1). Lipids were isolated from the plate and, after transmethylation, quantified by GC. Chlorophyll and inorganic phosphate were measured photometrically according to Lichtenthaler (1987) and Itaya and Ui (1966), respectively.

\section{Northern analysis}

Total RNA was isolated from Arabidopsis leaves, separated by agarose gel electrophoresis and blotted onto Nylon membranes (Sambrook et al., 1989). For hybridization, cDNA fragments derived from Arabidopsis galactolipid synthase genes were used: MGD1, MGD2, MGD3 (Awai et al., 2001; Jarvis et al., 2000); DGD1, DGD2 (Kelly and Dörmann, 2002).

\section{Electron microscopy}

Leaves were fixed for $2 \mathrm{~h}$ with glutaraldehyde $(2.5 \%)$ in sodiumpotassium phosphate buffer $(0.1 \mathrm{M}, \mathrm{pH} 7.0)$ including paraformaldehyde $(2 \%)$ and tannic acid $(0.2 \%)$. After washing with phosphate buffer, samples were incubated for $12 \mathrm{~h}$ in osmium tetroxide $(1 \%$ in $50 \mathrm{~mm}$ sodium-potassium phosphate buffer, $\mathrm{pH}$ 7.0). After washing with phosphate buffer, they were dehydrated in a graded series of ethanol followed by propylene oxide, incubated in a mixture of propylene oxide/ERL (v/v) and pure ERL (Spurr, 1969), and polymerized overnight at $60^{\circ} \mathrm{C}$. Ultra-thin sections were contrasted with uranyl acetate and lead citrate. Transmission electron micrographs were obtained with a Siemens 101 at $80 \mathrm{kV}$ electron microscope (Siemens http://www.siemens.com).

\section{Analysis of FAPEs by GC-MS}

The lipid ester fraction isolated by TLC of non-polar leaf lipids was extracted with chloroform/methanol (2:1), and the organic solvent evaporated with nitrogen gas. Lipid esters were dissolved in hexane and injected directly into GC-MS. GC-MS was carried out on an Agilent HP6890 Series GC with 5973 inert mass selective detector according to Ischebeck et al. (2006). Standards of FAPEs were synthesized from phytol (Aldrich http://www.sigmaaldrich.com) and 
different fatty acids (pentadecanoic acid, 15:0; palmitic acid, 16:0; oleic acid, 18:1; $\alpha$-linolenic acid, 18:3; Sigma, http://www.sigmaaldrich.com/) according to Gellerman et al. (1975). For quantification of FAPEs, a total lipid extract was obtained from leaves and 15:0-phytol added as internal standard. Lipids were directly injected into GC-MS, and FAPEs quantified using peak areas of total ion chromatograms. Because the peaks of 16:3-phytol and 16:0-phytol overlap, the amount of 16:0-phytol was calculated using extracted ion chromatograms of $m / z=278.3$.

\section{Chloroplast fractionation}

Chloroplasts from Arabidopsis plants raised on soil were isolated after homogenization of leaves according to Vidi et al. (2006). After hypotonic rupture of chloroplasts, sub-plastidial compartments were separated by centrifugation using a standard sucrose density gradient as described by Vidi et al. (2006). Western blot analysis [using antibodies against plastoglobulin 35 (PGL35); translocator at the outer chloroplast envelope 75 (TOC75); chlorophyll a binding protein $(\mathrm{CAB})$ ] was carried out to assess the distribution of plastoglobules, envelopes and thylakoids. The results of Western blots were analogous to those of Figure 2 of Vidi et al. (2006), and the gradient fractions were pooled accordingly. The gradient fractions 1-6 (F1) and 7-13 (F2) contained mostly plastoglobules; envelopes and low amounts of thylakoids were found in fractions 14-19 (F3); fractions 20-23 (F3) contained envelopes and thylakoids, and fractions 24-29 (F5) mostly thylakoids (Vidi et al., 2006). Lipids were extracted from the five fraction pools with chloroform/methanol (2:1), and total fatty acids and FAPEs were quantified by GC-FID and GC-MS, respectively.

\section{Acknowledgements}

Funding for this project was provided in part by the Deutsche Forschungsgemeinschaft (SFB 429, part B6). Felix Kessler and Claire Bréhélin were supported by the University of Neuchâtel and the NCCR 'Plant Survival'.

\section{References}

Anderson, W.H., Gellerman, J.L. and Schlenk, H. (1984) Effect of drought on phytyl wax esters in Phaseolus leaves. Phytochemistry, 23, 2695-2696.

Andersson, M.X., Stridh, M.H., Larsson, K.E., Liljenberg, C. and Sandelius, A.S. (2003) Phosphate-deficient oat replaces a major portion of the plasma membrane phospholipids with the galactolipid digalactosyldiacylglycerol. FEBS Lett. 537, 128132.

Austin, J.R., II, Frost, E., Vidi, P.-A., Kessler, F. and Staehelin, A. (2006) Plastoglobules are lipoprotein subcompartments of the chloroplast that are permanently coupled to thylakoid membranes and contain biosynthetic enzymes. Plant Cell, 18, 16931703.

Awai, K., Maréchal, E., Block, M.A., Brun, D., Masuda, T., Shimada, H., Takamiya, K.i., Ohta, H. and Joyard, J. (2001) Two types of MGDG synthase genes, found widely in both $16: 3$ and $18: 3$ plants, differentially mediate galactolipid syntheses in photosynthetic and nonphotosynthetic tissues in Arabidopsis thaliana. Proc. Natl Acad. Sci. USA, 98, 10960-10965.

Benson, A.A. (1971) Lipids of chloroplasts. In Structure and Function of Chloroplasts (Gibbs M., ed.). Berlin: Springer-Verlag, pp. 129148.
Bonaventure, G., Salas, J.J., Pollard, M.R. and Ohlrogge, J.B. (2003) Disruption of the FATB gene in Arabidopsis demonstrates an essential role of saturated fatty acids in plant growth. Plant Cell, 15, 1020-1033.

Browse, J., McCourt, P.J. and Somerville, C.R. (1986) Fatty acid composition of leaf lipids determined after combined digestion and fatty acid methyl ester formation from fresh tissue. Anal. Biochem. 152, 141-145.

Browse, J., Somerville, C.R. and Slack, C.R. (1988) Changes in lipid composition during protoplast isolation. Plant Sci. 56, 15-20.

Buchanan, M.S., Hashimoto, T. and Asakawa, Y. (1996) Phytoyl esters and phaeophytins from the hornwort Megaceros flagellaris. Phytochemistry, 41, 1373-1376.

Carrari, F., Coll-Garcia, D., Schauer, N., Lytovchenko, A., PalaciosRojas, N., Balbo, I., Rosso, M. and Fernie, A.R. (2005) Deficiency of a plastidial adenylate kinase in Arabidopsis results in elevated photosynthetic amino acid biosynthesis and enhanced growth. Plant Physiol. 137, 70-82.

Cranwell, P.A., Robinson, N. and Eglinton, G. (1985) Esterified lipids of the freshwater dinoflagellate Peridinium lomnickii. Lipids, 20, 645-651.

Cranwell, P.A., Jaworski, G.H.M. and Bickley, H.M. (1990) Hydrocarbons, sterols, esters and fatty acids in six freshwater chlorophytes. Phytochemistry, 29, 145-151.

Crawford, N.M. (1995) Nitrate: nutrient and signal for plant growth. Plant Cell, 7, 859-868.

Csupor, L. (1971) Das Phytol in vergilbten Blättern. Planta Med. 19, 37-40.

Dörmann, P., Voelker, T.A. and Ohlrogge, J.B. (1995a) Cloning and expression in Escherichia coli of a novel thioesterase from Arabidopsis thaliana specific for long chain acyl-acyl carrier proteins. Arch. Biochem. Biophys. 316, 612-618.

Dörmann, P., Hoffmann-Benning, S., Balbo, I. and Benning, C. (1995b) Isolation and characterization of an Arabidopsis mutant deficient in the thylakoid lipid digalactosyl diacylglycerol. Plant Cell, 7, 1801-1810.

Douce, R. and Joyard, J. (1980) Plant Galactolipids. In The Biochemistry of Plants, Vol. 4, Lipids: Structure and Function (Stumpf P.K., ed.). New York: Academic Press, pp. 321-362.

Essigmann, B., Güler, S., Narang, R.A., Linke, D. and Benning, C. (1998) Phosphate availability affects the thylakoid lipid composition and the expression of $S Q D 1$, a gene required for sulfolipid biosynthesis in Arabidopsis thaliana. Proc. Natl Acad. Sci. USA, 95, 1950-1955.

Estelle, M.A. and Somerville, C. (1987) Auxin-resistant mutants of Arabidopsis thaliana with an altered morphology. Mol. Gen. Genet. 206, 200-206.

García-Ferris, C., de los Ríos, A., Ascaso, C. and Moreno, J. (1996) Correlated biochemical and ultrastructural changes in nitrogenstarved Euglena gracilis. J. Phycol. 32, 953-963.

Gellerman, J.L., Anderson, W.H. and Schlenk, H. (1975) Synthesis and analysis of phytyl and phytenoyl wax esters. Lipids, 10, 656661.

Härtel, H., Dörmann, P. and Benning, C. (2000) DGD1-independent biosynthesis of extraplastidic galactolipids following phosphate deprivation in Arabidopsis. Proc. Natl Acad. Sci. USA, 97, 1064910654.

Ischebeck, T., Zbierzak, A.M., Kanwischer, M. and Dörmann, P. (2006) A salvage pathway for phytol metabolism in Arabidopsis. J. Biol. Chem. 281, 2470-2477.

Itaya, K. and Ui, M. (1966) A new micromethod for the colorimetric determination of inorganic phosphate. Clin. Chim. Acta, 14, 361366. 
Jarvis, P., Dörmann, P., Peto, C.A., Lutes, J., Benning, C. and Chory, J. (2000) Galactolipid deficiency and abnormal chloroplast development in the Arabidopsis MGD synthase 1 mutant. Proc. Natl Acad. Sci. USA, 97, 8175-8179.

Jouhet, J., Maréchal, E., Baldan, B., Bligny, R., Joyard, J. and Block, M.A. (2004) Phosphate deprivation induces transfer of DGDG galactolipid from chloroplast to mitochondria. J. Cell Biol. 167, 863-874.

Kaup, M.T., Froese, C.D. and Thompson, J.E. (2002) A role for diacylglycerol acyltransferase during leaf senescence. Plant Physiol. 129, 1616-1626.

Kelly, A.A. and Dörmann, P. (2002) DGD2, an Arabidopsis gene encoding a UDP-galactose dependent digalactosyldiacylglycerol synthase is expressed during growth under phosphate limiting conditions. J. Biol. Chem. 277, 1166-1173.

Kelly, A.A., Froehlich, J.E. and Dörmann, P. (2003) Disruption of the two digalactosyldiacylglycerol synthase genes DGD1 and DGD2 in Arabidopsis reveals the existence of an additional enzyme of galactolipid synthesis. Plant Cell, 15, 2694-2706.

Kunst, L., Browse, J. and Somerville, C. (1988) Altered regulation of lipid biosynthesis in a mutant of Arabidopsis deficient in chloroplast glycerol-3-phosphate acyltransferase activity. Proc. Nat Acad. Sci. USA, 85, 4143-4147.

Kutík, J., Nátir, L., Demmers-Derk, H.H. and Lawlor, D.W. (1995) Chloroplast ultrastructure of sugar beet (Beta vulgaris L.) cultivated in normal and elevated $\mathrm{CO}_{2}$ concentrations with two contrasted nitrogen supplies. J. Exp. Bot. 46, 1797-1802.

Laza, R.C., Bergman, B. and Vergara, B.S. (1993) Cultivar differences in growth and chloroplast ultrastructure in rice as affected by nitrogen. J. Exp. Bot. 44, 1643-1648.

Lichtenthaler, H.K. (1987) Chlorophylls and carotenoids: pigments of photosynthetic biomembranes. Methods Enzymol. 148, 350382.

López Alonso, D., Belarbi, E.-H., Fernández-Sevilla, J.M., RodriguezRuiz, J. and Molina Grima, E. (2000) Acyl lipid composition variation related to culture age and nitrogen concentration in continuous culture of the microalga Phaeodactylum tricornutum. Phytochemistry, 54, 461-471.

Malavolta, E., Nogueira, N.G.L., Heinrichs, R., Higashi, E.N., Rodríguez, V., Guerra, E., de Oliveira, S.C. and Cabral, C.P. (2004) Evaluation of nutritional status of the cotton plant with respect to nitrogen. Commun. Soil Sci. Plant Anal. 35, 1007-1019.

Mock, T. and Kroon, B.M.A. (2002) Photosynthetic energy conversion under extreme conditions. I. Important role of lipids as structural modulators and energy sink under $\mathrm{N}$-limited growth in Antarctic sea ice diatoms. Phytochemistry, 61, 41-51.

Murashige, T. and Skoog, F. (1962) A revised medium for rapid growth and bio assays with tobacco tissue cultures. Physiol. Plant. 15, 473-497.

Pacovsky, R.S. and Fuller, G. (1988) Mineral and lipid composition of Glycine-Glomus-Bradyrhizobium symbioses. Physiol Plant. 72, 733-746.

Patterson, G.W., Hugly, S. and Harrison, D. (1993) Sterols and phytyl esters of Arabidopsis thaliana under normal and chilling temperatures. Phytochemistry, 33, 1381-1383.

Peisker, C., Düggelin, T., Rentsch, D. and Matile, P. (1989) Phytol and the breakdown of chlorophyll in senescent leaves. J. Plant Physiol. 135, 428-432.

Pereira, A.S., Siqueira, D.S., Elias, V.O., Simoneit, B.R.T., Cabral, J.A., Francisco, R. and Neto, A. (2002) Three series of high molecular weight alkanoates found in Amazonian plants. Phytochemistry, 61, 711-719.

Poirier, Y., Thoma, S., Somerville, C. and Schiefelbein, J. (1991) A mutant of Arabidopsis deficient in xylem loading of phosphate. Plant Physiol. 97, 1087-1093.

Rise, M., Cojocaru, M., Gottlieb, H.E. and Goldschmidt, E.E. (1989) Accumulation of $\alpha$-tocopherol in senescing organs as related to chlorophyll degradation. Plant Physiol. 89, 1028-1030.

Rontani, J.F., Bonin, P.C. and Volkman, J.K. (1999) Production of wax esters during aerobic growth of marine bacteria on isoprenoid compounds. Appl. Environ. Microbiol. 65, 221-230.

Sambrook, J., Fritsch, E. and Maniatis, T. (1989) Molecular Cloning: A Laboratory Manual. Cold Spring Harbor, NY, USA: Cold Spring Harbor Laboratory Press.

Scheible, W.-R., Morcuende, R., Czechowski, T., Fritz, C., Osuna D., Palacios-Rojas, N., Schindelasch, D., Thimm, O., Udvardi, M.K. and Stitt, M. (2004) Genome-wide reprogramming of primary and secondary metabolism, protein synthesis, cellular growth processes, and the regulatory infrastructure of Arabidopsis in response to nitrogen. Plant Physiol. 136, 24832499.

Spurr, A.R. (1969) A low-viscosity epoxy resin embedding medium for electron microscopy. J. Ultrastruct. Res. 210, 57-69.

Stitt, M. (1999) Nitrate regulation of metabolism and growth. Curr. Opin. Plant Biol. 2, 178-186.

Tevini, M. and Steinmüller, D. (1985) Composition and function of plastoglobuli. II. Lipid composition of leaves and plastoglobuli during beech leaf senescence. Planta, 163, 91-96.

Valentin, H.E., Lincoln, K., Moshiri, F. et al. (2006) The Arabidopsis vitamin E pathway gene 5-1 mutant reveals a critical role for phytol kinase in seed tocopherol biosynthesis. Plant Cell, 18, 212 224.

Vidi, P.-A., Kanwischer, M., Baginsky, S., Austin, J.R., Csucs, G., Dörmann, P., Kessler, F. and Bréhélin, C. (2006) Proteomics identify Arabidopsis plastoglobules as a major site in tocopherol synthesis and accumulation. J. Biol. Chem. 281, 1122511234.

Wang, R., Okamoto, M., Xing, X. and Crawford, N.M. (2003) Microarray analysis of the nitrate response in Arabidopsis roots and shoots reveals over 1000 rapidly responding genes and new linkages to glucose, trehalose-6-phosphate, iron, and sulfate metabolism. Plant Physiol. 132, 556-567.

Wang, R., Tischner, R., Gutiérrez, R.A., Hoffman, M., Xing, X., Chen, M., Coruzzi, G. and Crawford, N.M. (2004) Genomic analysis of the nitrate response using a nitrate reductase-null mutant of Arabidopsis. Plant Physiol. 136, 2512-2522.

Webb, M.S. and Green, B.R. (1991) Biochemical and biophysical properties of thylakoid acyl lipids. Biochim. Biophys. Acta, 1060, 133-158

Wilkinson, J.Q. and Crawford, N.M. (1991) Identification of the Arabidopsis $\mathrm{CHL} 3$ gene as the nitrate reductase structural gene NIA2. Plant Cell, 3, 461-471.

Wilkinson, J.Q. and Crawford, N.M. (1993) Identification and characterization of a chlorate-resistant mutant of Arabidopsis thaliana with mutations in both nitrate reductase structural genes NIA1 and NIA2. Mol. Gen. Genet. 239, 289-297.

Ytterberg, A.J., Peltier, J.-B. and van Wijk, K.J. (2006) Protein profiling of plastoglobules in chloroplasts and chromoplasts; a surprising site for differential accumulation of metabolic enzymes. Plant Physiol. 140, 984-997. 